\title{
A Microstrip Antenna Design Using an Heuristic Algorithm
}

\author{
I Made Adhi Wiryawan ${ }^{1}$, Anugerah Galang Persada ${ }^{2}$, Maria Veronica Astrid W. ${ }^{3}$, Dyonisius Dony Ariananda ${ }^{4}$
}

\begin{abstract}
Microstrip antennas have several advantages. Some of them are that they have a compact shape and small dimensions. Moreover, they are also easy to be fabricated and easily connected as well as integrated with other electronic devices. Currently, designing antennas conventionally is limited by time, energy, and experience as well as expertise. As an alternative, a way to design antennas with revolutionary methods is developed using algorithms and computing. Algorithm design techniques can overcome limitations and automatically find practical solutions that usually take a long time to discover. The particle swarm optimization algorithm and a genetic algorithm can find solutions from microstrip antennas. Objective functions play an essential role in heuristic algorithms. With a proper objective function, simulation results are obtained on the particle swarm optimization algorithm with a return loss value of -47.837 , VSWR of 1.0083 , and impedance of $46.805 \Omega$. In contrast, the genetic algorithm

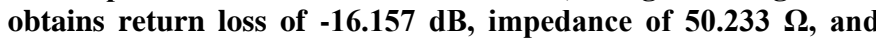
VSWR of 1.3687.
\end{abstract}

Keywords-Microstrip Antenna, Particle Swarm Optimization Algorithm, Heuristic Algorithm, Objective Function.

\section{INTRODUCTION}

At present, technological advances undergo rapid changes. The size of telecommunication devices has decreased significantly, and this decrease affects the antenna dimensions. It results in significant considerations for antenna design, especially the microstrip antennas. Moreover, as technology advances, the antenna design has proliferated and gets more difficult than in the previous years with the parameters inherent in the radiation patterns, bandwidth, and physical size. It makes the antenna design has been through a long process. In fact, the current manually-made antenna designs are carried out in a limited way because it requires expertise, significant experience, time, and also intensive labor. As an alternative, researchers have been investigating antenna design and optimization since the early 1990s [1]. This field has been evolving in the last few years in line with the increase in computer computing speed. Several methods have been utilized to optimize the antennas with varying successes; one of them is by using a heuristic algorithm [2].

Designing patch microstrip antenna parameters requires a trial and error process because previous studies are not systematic and the conclusion depends on the antenna under investigation, not in general. It's a challenge to design the dimensions of microstrip antenna to achieve the best a certain criterion [3]. Microstrip antenna design using Particle Swarm Optimization (PSO) algorithm provides optimization results on return loss and antenna dimensions [4].

1,2,3,4 Department of Electrical and Information Engineering Universitas Gadjah Mada, Jl. Grafika No. 2, Bulaksumur, Yogyakarta 55281(telp: 0274-552305; fax: 0274-552305; e-mail: ${ }^{1}$ madeadhiwiryawan@gmail.com, 22galang@ugm.ac.id, ${ }^{3}$ mariaveronicaastridw@gmail.com, ${ }^{4}$ dyonisius.dony@ugm.ac.id)
A PSO is one of heuristic algorithm parts that works by continuously calculating potential solutions using a quality reference. This algorithm optimizes problems by moving the particles/potential solutions within the problem scope using certain functions for the particles' position and speed. The particle's best solution influences a particle movement, and it is generally obtained from other particles. A group of particles is called the swarm, and this swarm will eventually move towards the best solution [5].

A Genetic Algorithm (GA) is a subset from a larger class of an evolutionary algorithm describing a set of techniques inspired by natural selection such as inheritance, mutation, and crossover. It requires a genetic representation from solution domain and fitness function to evaluate the solution domain. This technique generates a solution candidate population and utilizes fitness functions to determine an optimal solution by repeating each generation. The algorithm ends when the satisfying fitness level has been reached for the population, or the maximum has been achieved [6]. GA in designing microstrip antennas can provide optimal results on antenna impedance and faster convergence time [7].

The heuristic algorithms (PSO and GA) are expected to stimulate the microstrip antenna dimensions with return loss performance of $<-10 \mathrm{~dB}$, Voltage Standing Wave Ratio (VSWR) of 1-2, and impedance of \pm 50 ohms. Objective functions play a significant role as a reference to the utilized heuristic algorithm.

This paper discusses a microstrip antenna design using a heuristic algorithm in the form of GA and PSO algorithms. Part I discusses the background and purpose of the microstrip antenna design, part II discusses the antenna design and calculations, section III discusses the research method on the antenna, part IV presents the simulation results on the antenna. Part V presents the conclusion of this paper.

\section{PSO \& GA ALGORITHMS FOR MiCROSTRIP ANTENNA}

\section{A. Microstrip Antenna}

The microstrip antenna in Fig. 1 is a metal conductor attached to the ground plane in which there is a dielectric material. Microstrip antennas are antennas that have light mass, are easy to fabricate, and are small in size compared to other antenna types. The microstrip antenna is very suitable for current needs so that it can be integrated with other small telecommunication devices. However, the microstrip antenna also has some drawbacks, namely, the narrow frequency band, the small antenna gain, and antenna directivity, as well as its low efficiency [8]. Microstrip antennas generally consist of a conducting patch (b) and a ground plane (c) that serves as the antenna's ground; both are made of conductor material. The substrate separates both from dielectric material (d). A microstrip feed (a) is a conducting strip to connect patches to the edges. 


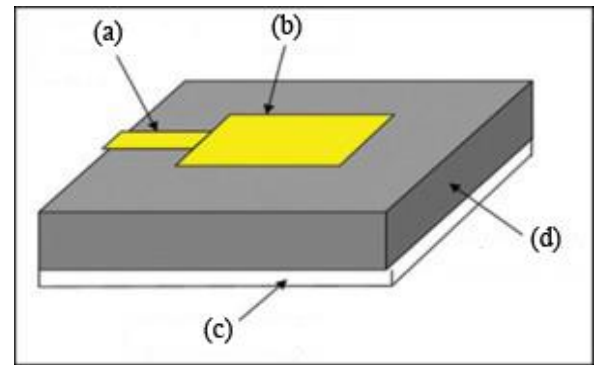

Fig. 1 Microstrip feed, (a) microstrip feed, (b) patch, (c) ground plane, (d) substrate [6].

\section{B. Genetic Algorithm (GA)}

GA is a method to seek out problems in the real world based on the genetic process within the living things, namely the generation development process in a population that naturally follows natural selection to survive [9]. Fig. 2 shows the flowchart of GA.

An initial population is a process of generating several individuals randomly or through specific procedures. The population size depends on the problem to be solved. A selection is used to obtain an excellent prospective parent by selecting individuals for the crossover and mutation process [4]. A crossover is a GA process involving two individuals acting as parents to form new chromosomes. A chromosome can also be modified using a mutation operator. The new generation population is created by selecting the fitness value. After several generations, this algorithm will converge to the best chromosome [10].

\section{Particle Swarm Optimization Algorithm}

Particles in the flowchart (Fig. 3) is a solution candidate for the problems to be solved [3]. Each particle has the velocity, position in the solution coordinate system, the best personal location $(\vec{p})$, and the best global location $(\vec{g})$. The particles in the PSO have two memories, cognitive memory, and social memory, that link to the best personal $(\vec{p})$ and the best global $(\vec{g})$. Naturally, each particle will try the locations around the best particular site. However, the particles are also aware of the location of many other particle crowds. It can be formulated into (1) and (2).

$$
\begin{gathered}
\vec{v}_{i}^{k+1}=w^{k} \vec{v}_{i}^{k}+c_{1} \vec{r}_{1, i}^{k} o\left(\vec{p}_{i}^{k}-\vec{x}_{i}^{k}\right) \\
+c_{2} \vec{r}_{2, i}^{k} o\left(\vec{g}_{i}^{k}-\vec{x}_{i}^{k}\right) \\
\vec{x}_{i}^{k+1}=\vec{x}_{i}^{k}+\vec{v}_{i}^{k+1} \Delta t .
\end{gathered}
$$

Equation (1) defines the $i^{\text {th }}$ particle velocity on the $k+1$ iteration, and (2) defines the position of $i^{\text {th }}$ particle in the $k+1$ iteration.

\section{Mathematical Calculation of the Microstrip Antenna}

In a rectangular microstrip antenna design, parameters of the used materials must be known beforehand, including the substrate thickness $(h)$, the dielectric constant $(\varepsilon r)$, and the working frequency $\left(f_{0}\right)$ The value is used to obtain the microstrip antenna's length and width. The equation used to find the microstrip antenna length is shown in (3) [1].

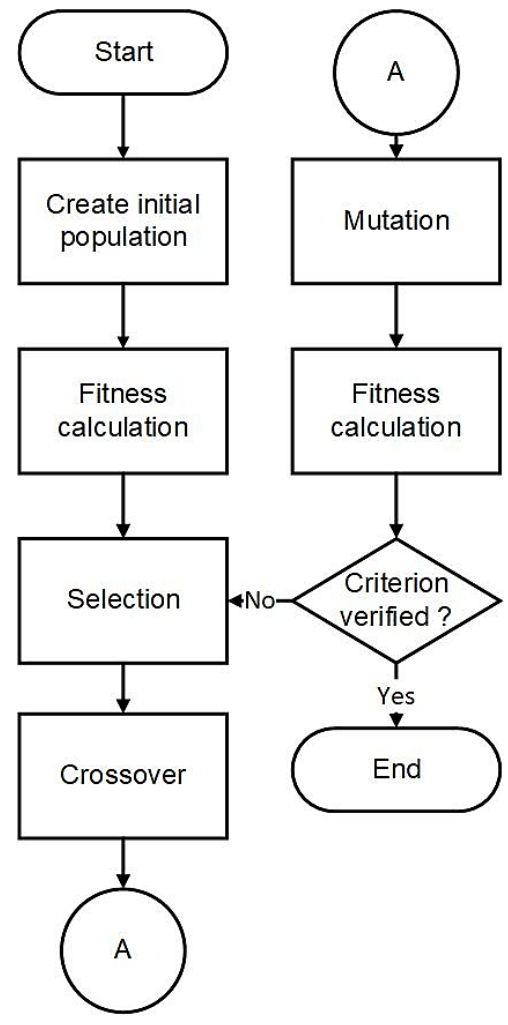

Fig. 2 Flowchart of a genetic algorithm.

$$
\begin{aligned}
& L=L_{e f f}-2 \Delta L \\
& W=\frac{c}{2 f_{o} \sqrt{\frac{\left(\varepsilon_{r}+1\right)}{2}}}
\end{aligned}
$$

whereas to determine the width of a microstrip antenna, (4) is employed [1].

Some parameters are calculated beforehand to obtain the width and length, namely, the effective length $\left(L_{e f f}\right)$, the length difference $(\Delta L)$, and the effective dielectric constant $\left(\epsilon_{\text {reff }}\right)$. These parameters can be calculated using (5) to (7) [1].

$$
\begin{gathered}
L_{e f f}=\frac{c}{2 f_{o} \sqrt{\epsilon_{\text {reff }}}} \\
\frac{\Delta L}{h}=0.412 \frac{\left(\varepsilon_{e}+0.3\right)\left[\frac{W}{h}+0.264\right]}{\left(\varepsilon_{e}-0.258\right)\left[\frac{W}{h}+0.813\right]} \\
\varepsilon_{e}=\frac{\varepsilon_{r}+1}{2}+\frac{\varepsilon_{r}-1}{2}\left(1+12 \frac{h}{W}\right)^{-\frac{1}{2}}
\end{gathered}
$$

where,

$$
\begin{aligned}
& c \quad=\text { speed of light }\left(3 \times 10^{8}\right)(\mathrm{m} / \mathrm{s}) \\
& f r=\text { working frequency }(\mathrm{Hz}) \\
& \epsilon_{\text {reff }}=\text { effective dielectric constant }(\mathrm{F} / \mathrm{m}) \\
& \epsilon_{r}=\text { substrate dielectric constant }(\mathrm{F} / \mathrm{m}) \\
& h \quad=\text { substrate thickness }(\mathrm{m}) \\
& W=\text { patch width }(\mathrm{m}) \\
& L \quad=\text { patch length }(\mathrm{m}) \\
& \Delta L=\text { length difference }(\mathrm{m}) \\
& L_{e f f}=\text { effective length }(\mathrm{m}) .
\end{aligned}
$$




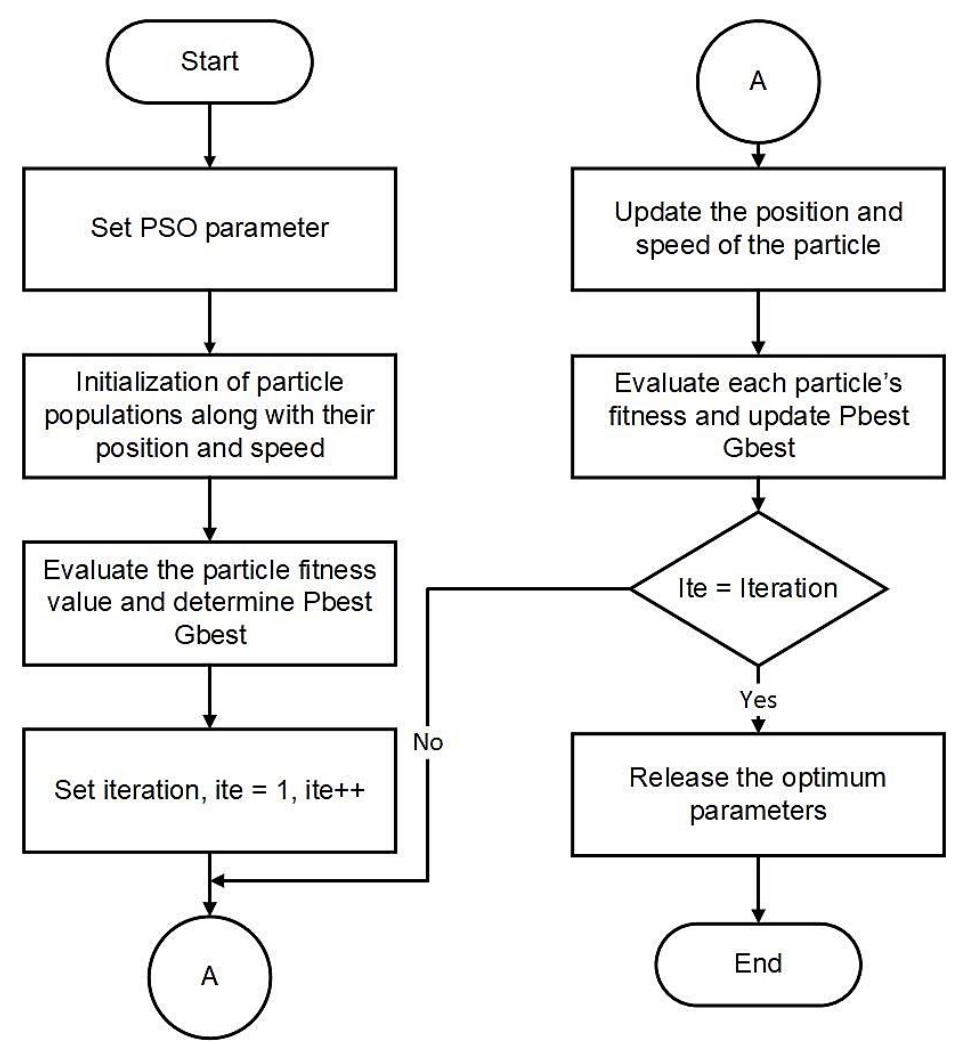

Fig. 3 A flowchart of the particle swarm optimization.

\section{E. Return Loss $\left(S_{11}\right)$}

Return loss is the amount of reflected power when the power is being transmitted from an antenna. Return loss is made smaller than $-10 \mathrm{~dB}$, which means that there is at least $90 \%$ of the power transmitted successfully. Therefore, the return loss should be less than $-10 \mathrm{~dB}$ to generate a considerable transmit power. The return loss can be calculated using (8) [1].

$$
\begin{gathered}
R(\mathrm{~dB})=10 \log (\text { incident power } / \text { reflected power }) \\
R(\mathrm{~dB})=10 \log (|V+| 2 /|V-| 2) \\
R(\mathrm{~dB})=20 \log (1 /|G|) .
\end{gathered}
$$

\section{F. Voltage Standing Wave Ratio (VSWR)}

The VSWR is a ratio between the maximum amplitude and the minimum amplitude of a reflected voltage when it is transmitted. A goof VSWR value is between 1 to 2 , which means that the amount of reflected voltage is insignificant. The VSWR can be calculated using the following (9) [1]

$$
V S W R=\frac{1+|\Gamma|}{1-|\Gamma|}
$$

\section{G. Impedance}

Input impedance is the ratio between the input voltage and the input current or the ratio of the corresponding components of the electric field with the magnetic field at a point. The impedance can be stated with (10) [1].

$$
Z_{A}=R_{A}+j X_{A}
$$

The antenna impedance value is made the same as the transmission channel impedance by feeding the feed. When the antenna impedance value is equal to the channel impedance value, the waves transmitted from the transmission line to the antenna can be transmitted entirely.

\section{METHODOLOGY}

The MATLAB and CST software were necessary for designing rectangular microstrip antenna with the heuristic algorithms. The designed antenna had a return loss $\left(S_{11}\right)$ specifications $<-10 \mathrm{~dB}, \mathrm{VSWR}<2$, and impedance of \pm 50 ohms. The design was carried out using a microstrip antenna dimension formula and using MATLAB AND CST software. The research flowchart is shown in Fig. 4.

\section{A. Microstrip Antenna Substrate Assessment}

The utilized substrate was made from Flame Resistant-4 material (FR-4) with a dielectric constant of $4.3(\varepsilon=4.3)$. The FR-4 substrate material was chosen because it was the most common, widely used, and had the lowest price compared to other substrate materials [11]. Moreover, the FR-4 substrate dielectric constant was considered sufficient to obtain an excellent microstrip antenna performance.

\section{B. Modeling of the Antenna Dimensional Constraint}

Dimension limits were significant to be administered so that the particles in the PSO algorithm worked efficiently. The determination of the search area limit value was carried out with a parsweep feature found in the CST software. The 


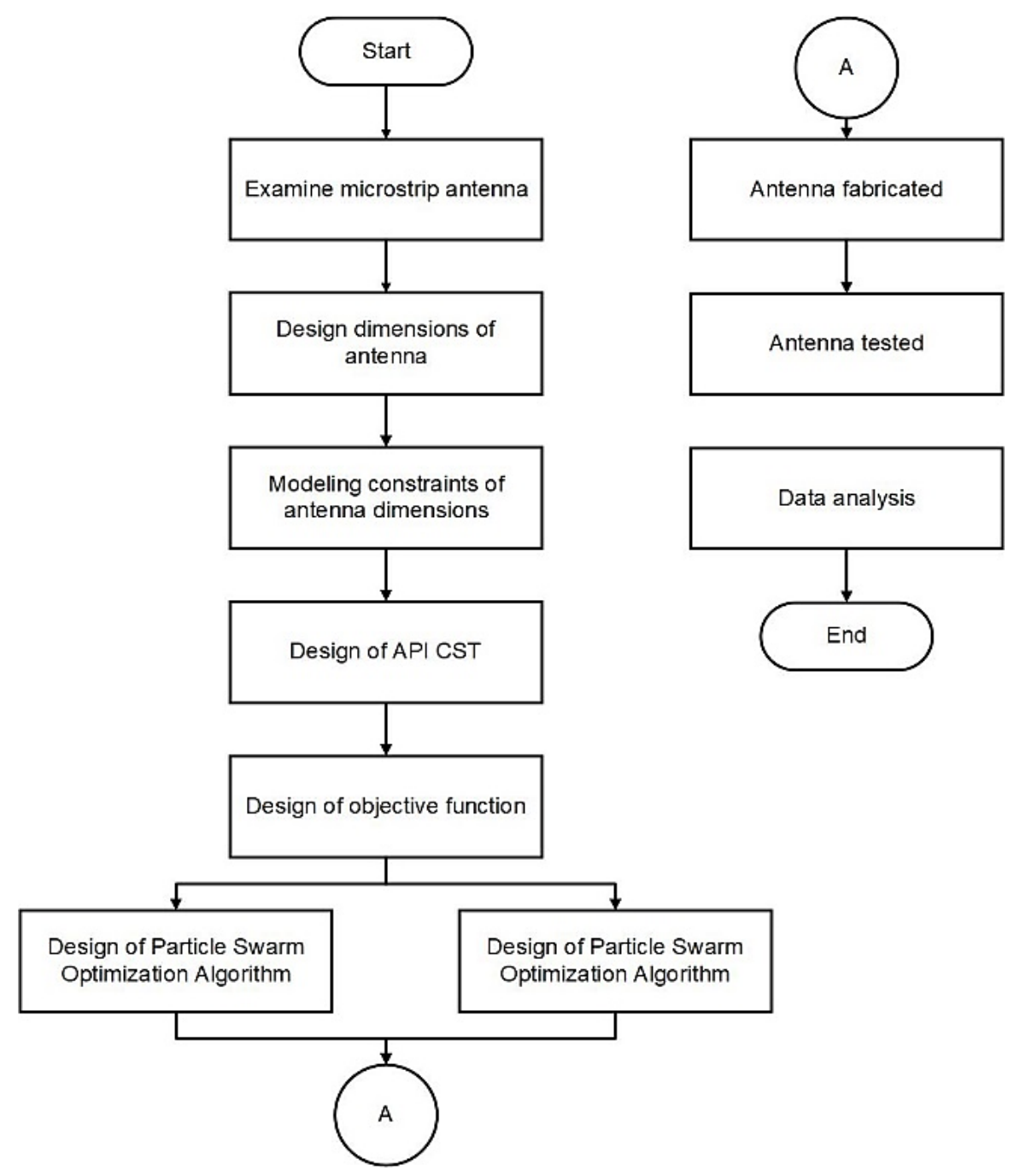

Fig. 4 Research flowchart.

obtained results were then analyzed for the best search area range.

To reach a value of $10 \mathrm{~dB}$, the microstrip antenna dimensions needed to have a range of $3 \mathrm{~mm}$ for the inset dept, feed width, patch length, ground length, ground width, and 0.4 for the gap feed. This range value was then used in the value of algorithm search area limitations. The seven parameters affecting the antenna performance were interconnected; therefore, the focus was not only on one parameter to obtain the best antenna performance.

\section{The API CST Design}

An API is a set of protocols in software that allows users to integrate two parts of the software or with different software simultaneously. The microstrip antenna design utilized the API from CST attached to the API-CST.m program code [9]. This API CST allowed the integration from MATLAB software and CST Studio Suite software. It aimed to speed up the computational process from MATLAB by providing functions separately.

This Api-CST application shortened the time needed to tun a microstrip antenna modeling computational process with algorithm because this function directly called up the CST Studio Suite. CST Studio Suite stored the antenna that had been modeled, and the values of return loss, VSWR, and antenna impedance were exported into text form. The export results were utilized to determine the microstrip antenna fitness value.

\section{Objective Function Design}

The development of the made objective functions considered the return loss $\left(S_{11}\right)$, VSWR, and impedance parameters. These three parameters were selected because they were the basis of a microstrip antenna performance. The equation that has been made is as follows.

$$
\begin{aligned}
& \text { Return loss }=\left\{\begin{array}{cc}
\left|S_{11}\right| & \text { Return loss } \leq-10 \\
\left|S_{11}\right| * 0.5 & \text { Return loss } \leq-6 \\
\left|S_{11}\right| * 0.2 & \text { otherwise }
\end{array}\right. \\
& \text { Impedance }= \\
& \int \text { Imp Impedans } \leq 53 \& \text { Impedans } \geq 47 \\
& \{\text { Imp } * 0.5 \text { Impedans } \leq 60 \& \text { Impedans } \geq 40 \\
& r \operatorname{cs} 11=-X_{7}+X_{6}-X_{5}+X_{4}-X_{3}+X_{2}-X_{1}+c
\end{aligned}
$$




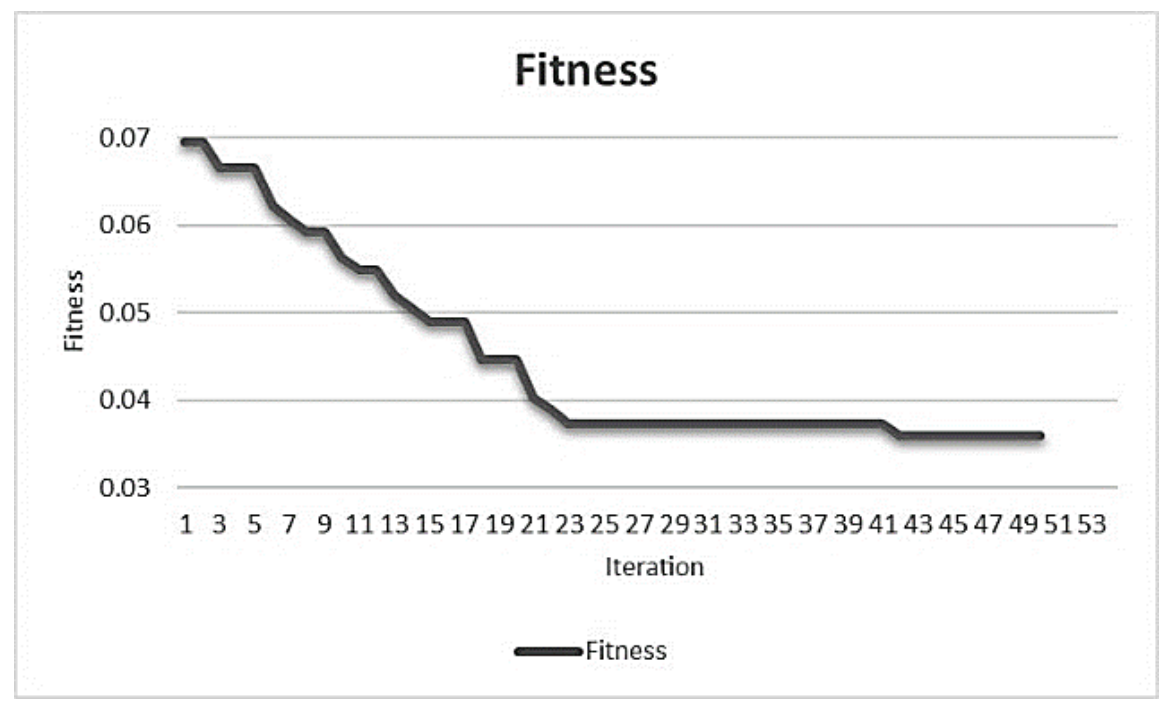

Fig. 5 Fitness of particle swarm optimization algorithm.

where,

$$
\begin{aligned}
& X_{7}=5.04419838626397 e^{-12} * a b s\left(S 11^{7}\right) \\
& X_{6}=1.09358319832468 e^{-9} * a b s\left(S 11^{6}\right) \\
& X_{5}=1.06137541377608 e^{-7} * a b s\left(S 11^{5}\right) \\
& X_{4}=6.18059647075924 e^{-6} * a b s\left(S 11^{4}\right) \\
& X_{3}=0.000241978763014699 * a b s\left(S 11^{3}\right) \\
& X_{2}=0.00655464901561200 * a b s\left(S 11^{2}\right) \\
& X_{1}=0.114933544102625 * a b s(S 11) \\
& c=0.999838720479687
\end{aligned}
$$$$
r c i=X_{9}-X_{8}+X_{7}-X_{6}+X_{5}-X_{4}+X_{3}-X_{2}+X_{1}-c(14)
$$

where,

$$
\begin{aligned}
& X_{9}=2.38093408339563 e^{-22} * I m p^{9} \\
& X_{8}=5.92570607293199 e^{-19} * I m p^{8} \\
& X_{7}=5.99948993966540 e^{-16} * I m p^{7} \\
& X_{6}=3.32183008032240 e^{-13} * I m p^{6} \\
& X_{5}=1.13295741646559 e^{-10} * I m p^{5} \\
& X_{4}=2.53240780552285 e^{-8} * I m p^{4} \\
& X_{3}=3.85169229387355 e^{-6} * I^{3} p^{3} \\
& X_{2}=0.000410576828154236 * \operatorname{Im} p^{2} \\
& X_{1}=0.0318422748895992 * \operatorname{Im} p \\
& c=0.919500776991153
\end{aligned}
$$

$$
f=|(r c s 11+r c i)|
$$

where,

$$
\begin{array}{ll}
r c s 11 & =\text { reflection coefficient } \\
r c i & =\text { reflection coefficient relation to load impedance } \\
S_{11} & =\text { return loss }(\mathrm{dB}) \\
\operatorname{Imp} & =\text { impedance }(\Omega) \\
f & =\text { fitness. }
\end{array}
$$

A constraint from the designed objective function was given to the return loss and impedance. The constraint value was
TABLE I

The Five BEST CANDIDATES FOR THE COMBINED OBJECTIVE FunCTION

\begin{tabular}{|l|l|l|l|l|}
\hline Number & $\begin{array}{c}\text { Return } \\
\text { loss } \\
(\mathbf{d B})\end{array}$ & $\begin{array}{c}\text { Impedance } \\
(\boldsymbol{\Omega})\end{array}$ & VSWR & Fitness \\
\hline 1 & -47.837 & 46.805 & 1.0083 & 0.035940 \\
\hline 2 & -45.400 & 46.889 & 1.0110 & 0.037348 \\
\hline 3 & -45.385 & 46.887 & 1.0110 & 0.037381 \\
\hline 4 & -45.375 & 46.887 & 1.0110 & 0.037389 \\
\hline 5 & -45.745 & 46.722 & 1.0105 & 0.038847 \\
\hline
\end{tabular}

based on the antenna performance characteristics that were considered to work well.

\section{ANALYSIS}

Antenna performance is assessed from several parameters, such as loss $\left(\mathrm{S}_{11}\right)$, VSWR, and impedance. After the antenna design with the algorithm was completed and fabricated, the simulation results using MATLAB and CST Microwave Studio software are shown as follows.

\section{A. Simulation of Particle Swarm Optimization Algorithm}

The PSO algorithm uses an objective function as the particle destination determiner. The algorithm can search the global minimum with parameters of 15 particles and 10 iterations, inertia weights of 0.9 and 0.4 , cognitive memory $\left(c_{1}\right)$ value of 2 , and social memory $\left(c_{1}\right)$ value of 2 . The fitness values are shown in Fig. 5.

From the fitness, the five best results are taken to be compared with return loss performance, the VSWR, and the generated impedance. The five candidates are shown in Table I. It shows that the PSO algorithms can design antenna dimensions with the desired performance.

\section{B. Genetic Algorithms Simulation}

The GA uses a combined objective function as the fitness benchmark. The algorithm can run to find the optimal value with a global minimum, with a population of sixteen with four 


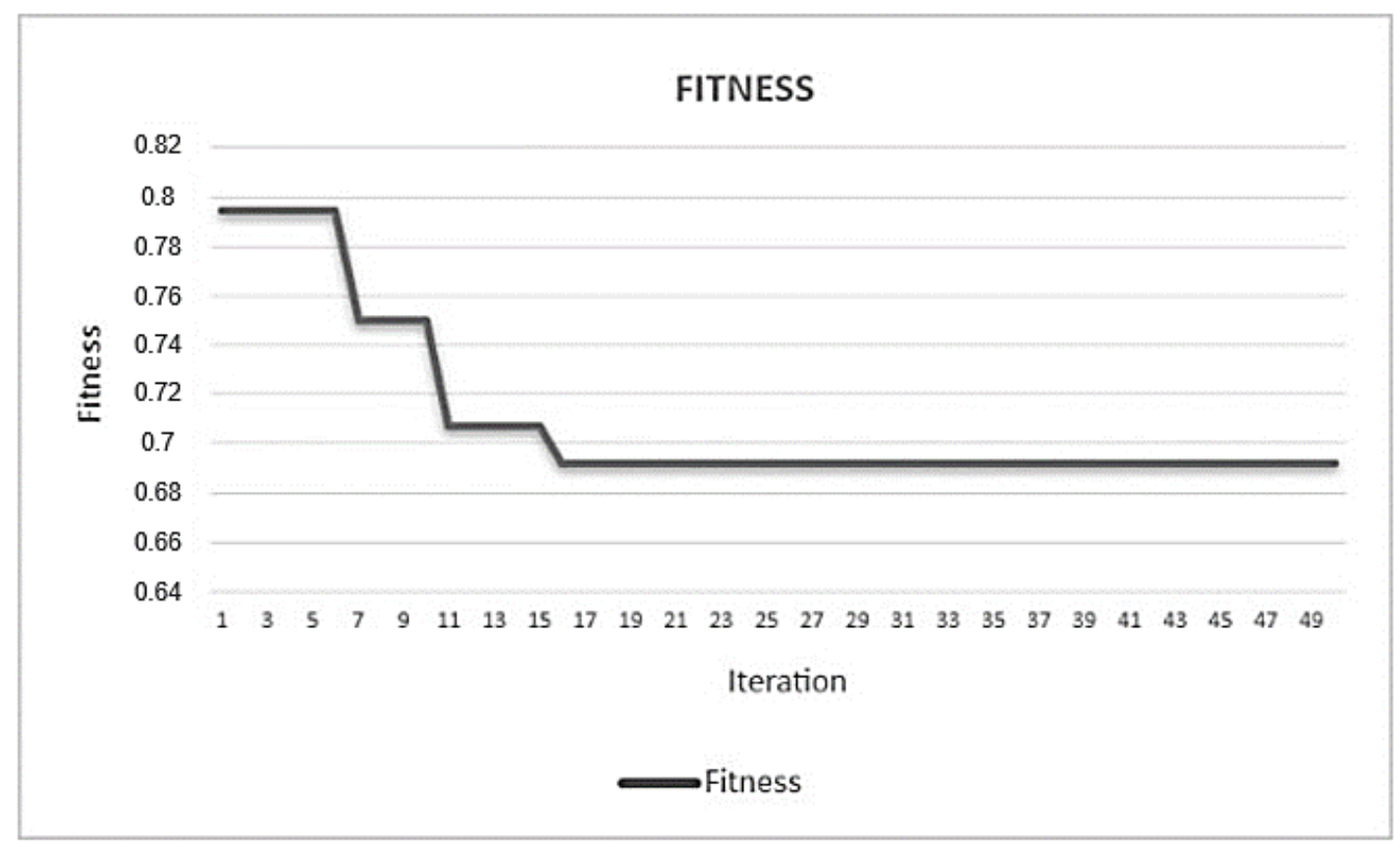

Fig. 6 Fitness of genetic algorithm.

TABLE II

The Five Best Combined OBJeCtive FunCtion CANDIDATES

\begin{tabular}{|l|l|l|l|l|}
\hline Number & $\begin{array}{c}\text { Return Loss } \\
(\mathbf{d B})\end{array}$ & $\begin{array}{c}\text { Impedance } \\
(\mathbf{\Omega})\end{array}$ & VSWR & Fitness \\
\hline 1 & -16.157 & 50.233 & 1.3687 & 0.6916 \\
\hline 2 & -16.116 & 50.231 & 1.3708 & 0.6923 \\
\hline 3 & -15.193 & 50.233 & 1.4212 & 0.7072 \\
\hline 4 & -14.704 & 53.854 & 1.4510 & 0.7499 \\
\hline 5 & -12.059 & 53.854 & 1.6649 & 0.7946 \\
\hline
\end{tabular}

TABLE III

Five FABRICATIONS OF THE BEST CANDIDATES FOR PARTICLE SWARM OPTIMIZATION COMBINED OBJECTIVE FUNCTIONS

\begin{tabular}{|c|c|c|c|}
\hline $\begin{array}{c}\text { Return Loss } \\
(\mathbf{d B})\end{array}$ & $\begin{array}{c}\text { Impedance } \\
(\mathbf{\Omega})\end{array}$ & VSWR & Fitness \\
\hline-10.7217169 & 37.5869729 & 1.820292 & 1.2106 \\
\hline-9.61736600 & 92.7038520 & 1.987168 & 1.4943 \\
\hline-9.61212810 & 95.6386440 & 1.988058 & 1.4946 \\
\hline-4.00504500 & 97.4681050 & 4.414050 & 1.8313 \\
\hline-4.26590125 & 90.2970670 & 4.153760 & 1.8258 \\
\hline
\end{tabular}

chromosomes, several iterations of 50 times, and a mutation value of 0.1 . The fitness values are shown in Fig. 6 .

From the fitness results, the five best are taken to be compared with the return loss characteristic performance, VSWR, and the generated impedance. The five candidates are shown in Table II.

\section{Antenna Fabrication}

The microstrip antenna was fabricated using dimensional references from the data that had been obtained. Fabrication was carried out through a third party, namely Spectra, in Bandung, West Java. The fabrication result is not satisfactory because there is an issue with the precision of the used dimensions due to the machine limitations.
TABLE IV

FIVE FABRICATIONS OF THE BEST CANDIDATES FOR GENETIC ALGORITHMS COMBINED OBJECTIVE FUNCTIONS

\begin{tabular}{|c|c|c|c|}
\hline $\begin{array}{c}\text { Return Loss } \\
(\mathbf{d B})\end{array}$ & $\begin{array}{c}\text { Impedance } \\
(\mathbf{\Omega})\end{array}$ & VSWR & Fitness \\
\hline-10.6772693 & 49.275263 & 1.8268 & 0.7892 \\
\hline-9.96851325 & 48.020119 & 1.9298 & 0.8151 \\
\hline-7.26031932 & 56.424294 & 2.5304 & 0.9064 \\
\hline-6.77572366 & 57.842693 & 1.6925 & 1.1199 \\
\hline-11.2571911 & 41.943951 & 1.7533 & 1.1729 \\
\hline
\end{tabular}

The microstrip antenna test was still carried out to test the designed combined objective functions, whether it worked well on the fabricated microstrip antenna or not. The fabricated microstrip antenna was measured using mini VNA to understand its performance. The performances are shown in Table III and Table IV. There is an impedance irrelevance in the fabricated antenna. Many factors cause the impedance irrelevance, one of which is an error in soldering the SMA port into the microstrip antenna.

\section{Conclusions}

Based on the discussion results, it can be concluded that the antenna that is designed using GA and the PSO has met the required criteria, namely, return loss $\left(\mathrm{S}_{11}\right),-10 \mathrm{~dB}$, antenna gain $.2 .5 \mathrm{~dB}$, frequency bandwidth $8.79 \mathrm{GHz}$, and VSWR $<1.8$. Therefore, this antenna can work on $5 \mathrm{G}$ networks.

\section{REFERENCES}

[1] Balanis, Antenna Theory: Analysis and Design, Hoboken, USA: Wiley, 1982.

[2] K.M. Luk, "The Importance of the New Developments in Antennas for Wireless Communications," Proc. IEEE, Vol. 99, No. 12, pp. 2082-2084, 2011. 
[3] N. Jin and Y. Rahmat-Samii, "Parallel Particle Swarm Optimization and Finite-Difference Time-Domain (PSO/FDTD) Algorithm for Multiband and Wide-Band Patch Antenna Designs," IEEE Transactions on Antennas and Propagation, Vol. 53, No. 11, pp. 3459-3468, 2005.

[4] H.S. Girija, R. Sudhakar, K.M.A. Kadhar, T.S. Priya, S. Ramanathan, and G. Anand, "PSO Based Microstrip Patch Antenna Design for ISM Band," 6th International Conference on Advanced Computing \& Communication Systems (ICACCS), 2020, pp. 1209-1214.

[5] R. Umar, F. Mohammed, M. Deriche, and A.U.H. Sheikh, "Hybrid Cooperative Energy Detection Techniques in Cognitive Radio Networks," in Handb. Res. Software-Defined Cogn. Radio Technol. Dyn. Spectr. Manag., Vol. 1, N. Kaabouch, Ed, Pennsylvania, USA: IGI Global, 2012, pp. 1-37.

[6] D.T. Pham and D. Karaboga, Intelligent Optimisation Techniques: Genetic Algorithms, Tabu Search, Simulated Annealing and Neural Networks, London, UK: Springer London, 2000.
[7] D.F. Poveda-Pulla, J.V. Dominguez-Paute, L.F. Guerrero-Vásquez, P.A Chasi-Pesantez, J.O. Ordoñez-Ordoñez, and P.E. Vintimilla-Tapia, "Optimization Designs in Patch Antennas Using Nature-inspired Metaheuristic Algorithms: A Review," 2018 IEEE Biennial Congress of Argentina, ARGENCON 2018, 2018, pp. 1-8.

[8] Y. La Elo, F.Y. Zulkifli, and E.T. Rahardjo, "Design of Wideband Microstrip Antenna with Parasitic Element for 4G/LTE Application," 15th Int. Conf. on Quality in Research (QiR): Int. Symp. on Electrical and Computer Engineering, 2017, pp. 110-113.

[9] M. Mitchell, An Introduction to Genetic Algorithms, Cambridge, USA: MIT Press, 1998.

[10] (2018) "Bahan PCB umum," [Online], http://id.bestcircuitboard.com/ info/common-pcb-materials-28156842.html, access date: 26-Jul-2019.

[11] S. Symeonidis (2018) "CST-MATLAB-API," [Online], https://zenodo.org/record/1237969\#. XX7s9qTVLIU, access date: 25Jul-2019. 